\title{
Minimization of $\mathrm{CaF}_{2}$ spherical surface deformation caused by annealing
}

\author{
František Procháska $\oplus^{\mathrm{a}}, *$ Matěj Machek $\odot,{ }^{\mathrm{b}}$ Jan Václavík, ${ }^{\mathrm{a}}$ \\ and Vasyl Karabyn ${ }^{\mathrm{a}}$

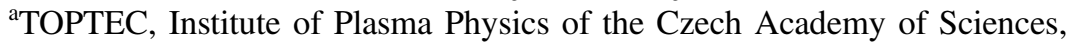 \\ Sobotecká, Turnov, Czech Republic \\ ${ }^{b}$ Institute of Geophysics of the Czech Academy of Sciences, \\ Boční II, Prague, Czech Republic
}

\begin{abstract}
We explore causes and possible techniques to minimize shape deformation of highprecision monocrystalline calcium fluoride optical surface formed during thermal annealing. Due to the anisotropic mechanical properties of calcium fluoride crystals, machining of lens shapes introduces defects into the crystal lattice. The thermal annealing thus leads to activation of the processes of recovery, resulting in the formation of characteristic surface structures causing both shape error and increased microroughness. The surface deformation can be gradually minimized by thermal treatment of the optical element and subsequent polishing steps to the order of units of nanometers, so they do not represent a fundamental problem for optical performance. (1) The Authors. Published by SPIE under a Creative Commons Attribution 4.0 International License. Distribution or reproduction of this work in whole or in part requires full attribution of the original publication, including its DOI. [DOI: 10.1117/1.OE.60.11.115101]
\end{abstract}

Keywords: $\mathrm{CaF}_{2}$ processing; $\mathrm{CaF}_{2}$ crystallography; $\mathrm{CaF}_{2}$ residual stress; $\mathrm{CaF}_{2}$ annealing.

Paper 20210779 received Jul. 21, 2021; accepted for publication Oct. 22, 2021; published online Nov. 1, 2021.

\section{Introduction}

In recent times, crystalline materials have been increasingly used in the field of ultraprecision optics for high-performance optical systems, including systems for space. One of the cases realized in the TOPTEC Centre is the optical telescope of the FLORIS satellite fluorescence spectrometer designed for observing photosynthetic activity from orbit within the ESA FLEX mission. ${ }^{1}$

FLORIS is a push-broom hyperspectral imager, flying on a medium size platform, that measures the vegetation fluorescence in the spectral range between 500 and $780 \mathrm{~nm}$ at medium spatial resolution $(300 \mathrm{~m})$ and over a swath of $150 \mathrm{~km}$. It accommodates an imaging spectrometer with a very high spectral resolution $(0.3 \mathrm{~nm})$ to measure the fluorescence spectrum within two oxygen absorption bands. Regarding optical design, the FLORIS telescope is the Petzval type objective with four spherical (two from monocrystalline calcium fluoride: $\mathrm{CaF}_{2}$ ) and one aspheric lens. It has a real entrance pupil located $75 \mathrm{~mm}$ in front of the first lens, where the instrument aperture stop is accommodated, and it is telecentric in the image focal plane. It guarantees good image quality up to $F \#=3.1$ in the high-resolution (HR) spectral band $(\mathrm{FOV}= \pm 5.4 \mathrm{deg} \times 0.0 \mathrm{deg}$ ) and to $F \#=6.5$ in the low-resolution (LR) spectral band $(\mathrm{FOV}= \pm 5.4 \mathrm{deg} \times 1.1 \mathrm{deg})$. A smaller $F \#$ is needed in the HR spectral band for radiometric constraints (lower input radiance and higher spectral resolution with respect to the LR spectrometer). Optical system radial distortion is $<0.2 \%$ and WFE RMS is $<0.23$ waves in HR $(0.14$ waves in LR) by design. Due to the high spectral resolution demand, the fundamental requirement is also stray light, which is limited to avoid pollution of the fluorescence signal; the important contribution is the spectral stray light, which comes from the light scattered by the telescope and spectrometer optical elements and which defines very tight requirements for the optical elements surface microroughness and mid-spatial frequencies (MSF) content. ${ }^{1}$

*Address all correspondence to František Procháska, prochaska@ipp.cas.cz 
Table $1 \mathrm{CaF}_{2}$ L1 R84.123 optical elements mandatory specification.

\begin{tabular}{ll}
\hline \hline Radius & 84.132 ( $\pm 0.05 \%) \mathrm{CX}$ \\
Surface shape error & $316.4 \mathrm{~nm}$ PV; $63.28 \mathrm{~nm}$ RMS \\
$\begin{array}{ll}\text { Microroughness }(0.7 \text { to } 0.007 \mathrm{~mm} \text { spatial } \\
\text { sampling using } 5 \times \text { NewView Zygo objective) }\end{array}$ \\
\hline \hline
\end{tabular}

From the tolerance analysis realized by the optical design team outside Toptec Centre, in which the influence of both MSF and microroughness on the system optical performance was detail-evaluated, the mandatory requirements for production specifications of the telescope optical elements were determined (for example, see Table 1).

As mentioned, two convex spherical lenses made from monocrystalline $\mathrm{CaF}_{2}$ are used. This material is popular with designers for its exceptional optical properties, especially for the wide transmittance range of $350 \mathrm{~nm}$ to $7 \mu \mathrm{m}$, high refractive index homogeneity, and low optical dispersion value. ${ }^{2}$ Nevertheless, it introduces fundamental complications to traditional processing chains, such as the right choice of crystallographic orientations for machining, problematic chemical and mechanical resistance, sensitivity to thermal shocks, etc., which greatly influence the production of such optical elements. To achieve the required optical quality, it is often necessary to use special machining processes, such as grinding and polishing with diamond slurries, single point diamond turning with laser assistance, ${ }^{3}$ float polishing, ${ }^{4}$ ion beam figuring (IBF), or magnetorheological finishing. ${ }^{5}$

Another significant complication occurs during the processing of spherical as well as aspherical elements made of the $\mathrm{CaF}_{2}$ (111) material, in which, due to the surface curvature, there is a transition between different crystallographic planes. The anisotropy of the chemical-mechanical properties of a $\mathrm{CaF}_{2}$ single crystal leads to different removal rates in certain parts of the processed surface and to the formation of a characteristic surface shape distortion with highs and lows varying periodically at $120 \mathrm{deg}$ (Fig. 1), ${ }^{6,7}$ which it is difficult to subsequently minimize without CNC subaperture correction polishing.

$\mathrm{CaF}_{2}$ is a soft and brittle material that exhibits crystalline anisotropy causing variation in the hardness and Young's modulus of the machined surface ${ }^{7}$ as well as stored residual stress, ${ }^{8}$ which leads to changes in the material deformation and removal mechanism depending on the orientation of the $\mathrm{CaF}_{2}$ crystal lattice and contact stress during surface processing. ${ }^{9-11}$ The $\mathrm{CaF}_{2}$ crystal anisotropy thus causes transition between ductile and brittle modes of material removal during the processing of (a)spherical shapes made of $\mathrm{CaF}_{2}$ (111). Ductile mechanisms of material removal are generated by plastic flow caused by the dislocation movement according

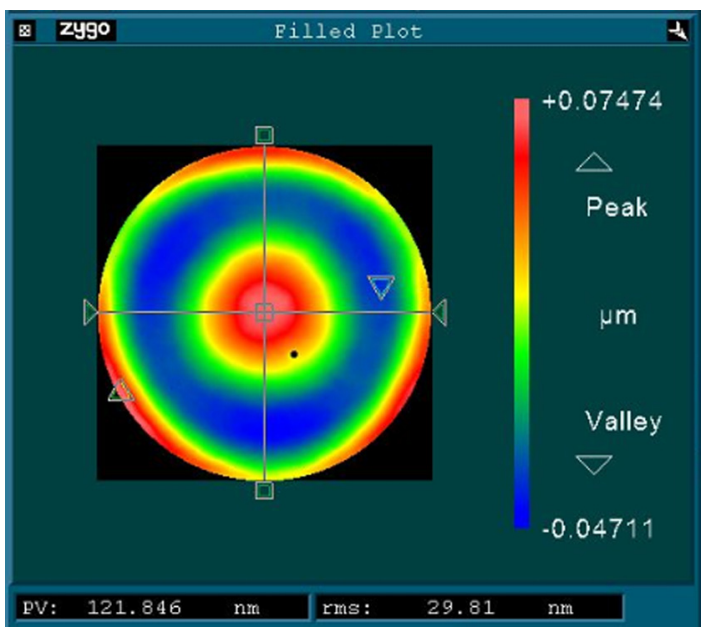

Fig. 1 Trifoil surface form structure on a $\mathrm{CaF}_{2}(1,1,1)$ material due to crystal orientation. Typical result of $\mathrm{CaF}_{2}$ FLORIS polishing experiment before annealing realized at TOPTEC. 


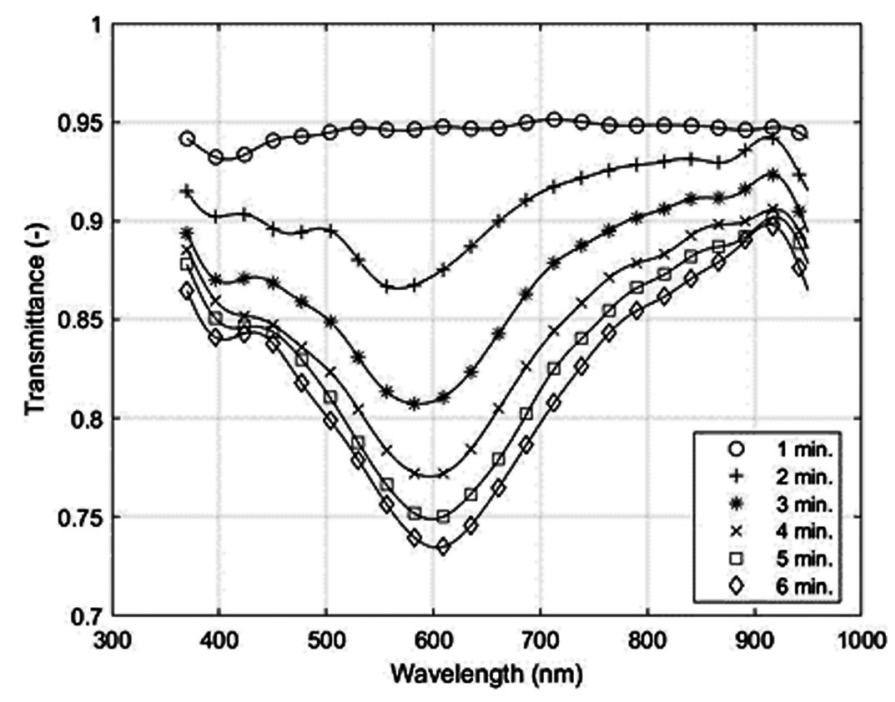

Fig. 2 Loss of transmittance of the $\mathrm{CaF}_{2}$ sample due to $\mathrm{Ar}^{+}$ion beam impact (intensity $80 \mu \mathrm{A} / \mathrm{cm}^{2}$, average energy $120 \mathrm{eV}$ ); results from FLORIS coating experiments realized at TOPTEC.

to a low temperature operating $\{100\}\langle 011\rangle$ slip system. ${ }^{11,12}$ The brittle mechanism is, on the other hand, governed by fracture initialization along $\{111\}$ and $\{110\}$ cleavage planes.

From the processing point of view, another significant property of $\mathrm{CaF}_{2}$ connected to its crystal lattice is the presence of local defects and the related formation of color centers due to irradiation by energetic particles, ${ }^{13,14}$ which can manifest either at shape IBF correction or at surface finalization by optical coating, when it is often necessary to use an assistance ion source $^{15}$ (see Fig. 2). However, the local defect formation also often occurs during the shape machining steps, especially during grinding or due to the presence of foreign chemical elements, in the crystal growing process. In any case, the presence of local defects leads to an increase in the level of internal stress. Internal stress and the amount of color centers can be minimized by annealing at temperatures above $300^{\circ} \mathrm{C} .^{13}$

Annealing is a process of recovery at static conditions that removes dislocations of crystal lattice, such as vacancies and interstitials forming the color centers in $\mathrm{CaF}_{2}$, from its crystal structure. However, annealing also mobilizes dislocations present in the crystal structure through their glide, climb, and cross-slip in accordance with the operating slip systems. ${ }^{16-18}$

As mentioned, as in the case of the FLORIS spectrometer lenses realized at the TOPTEC Centre, during the $\mathrm{CaF}_{2}$ optical element processing and finalization using optical coatings, it is often inevitable to include thermal treatment in the form of annealing (in our case, mainly to suppress the effect of color centers). However, this leads to complicated processes at the level of the crystal lattice, which result in both shape deformations and an increase in the achieved microroughness. To solve this issue, our article is devoted to their research and presents a possibility of minimizing their adverse effects.

\section{Experiment}

To study the behavior of the $\mathrm{CaF}_{2}$ spherical lenses during annealing, a series of experiments combining annealing and polishing by diamond slurry on a pitch pad was performed. The set of two parallel experiments was realized on FLORIS convex spherical lenses L1 with an optical diameter of $90 \mathrm{~mm}$, radius of curvature $84.132 \mathrm{~mm}$, and central thickness of $29 \mathrm{~mm}$.

In the first phase, the test lenses were polished and precisely corrected by IBF (the used setting is shown in Table 2) to a surface form error of around $5 \mathrm{~nm}$ RMS and then annealed twice at $350^{\circ} \mathrm{C}$ (ramp-up to $350^{\circ} \mathrm{C}$ with a gradient of $1^{\circ} \mathrm{C} / \mathrm{min}$, hold for $4 \mathrm{~h}$, naturally cool in an oven to room temperature). Final annealing was performed at $500^{\circ} \mathrm{C}$ with the same temperature 
Procháska et al.: Minimization of $\mathrm{CaF}_{2}$ spherical surface deformation...

Table 2 IBF setting for $\mathrm{CaF}_{2} \mathrm{~L} 1$ lenses precise correction.

\begin{tabular}{lc} 
Argon flow rate $(\mathrm{sccm})$ & 2 \\
Beam actual voltage $(\mathrm{V})$ & 1000 \\
Beam actual current $(\mathrm{mA})$ & 3.2 \\
Acc actual voltage $(\mathrm{V})$ & -500 \\
Acc actual current $(\mathrm{mA})$ & 1 \\
HF generator forward power $(\mathrm{W})$ & 60 \\
\hline \hline
\end{tabular}

gradients. Finally, annealing at $500^{\circ} \mathrm{C}$ was performed. In the second phase, the lenses were again classically ground and polished to remove the deformations and structures created in the previous phase, followed by repeated annealing at $350^{\circ} \mathrm{C}$. In the third phase, the lenses were only repolished and once more annealed twice at $350^{\circ} \mathrm{C}$. Before and after each experimental step, stitching interferometric shape error measurement of the lens optical diameter using QED ASI and WLI microroughness measurement at $5 \times$ magnification (field of view $1.4 \times 1.0 \mathrm{~mm}$ ) were performed.

\section{Results}

The results obtained in the first phase of the experiments are shown in Figs. 3 and 4, from which a significant deformation of the shape represented by the increasing surface error RMS value and the formation of a characteristic surface structure during annealing at a temperature of $350^{\circ} \mathrm{C}$ is evident. Subsequent repetition of the annealing experiment at $350^{\circ} \mathrm{C}$ led to virtually identical results. However, upon later following annealing at $500^{\circ} \mathrm{C}$, the shape deformation increased further. Regarding surface microroughness, due to the structure formation, its value increased from an initial 0.8-nm RMS to 2-nm RMS after annealing. The surface morphology after the first phase of annealing is characterized by periodically varying highs and lows mutually positioned

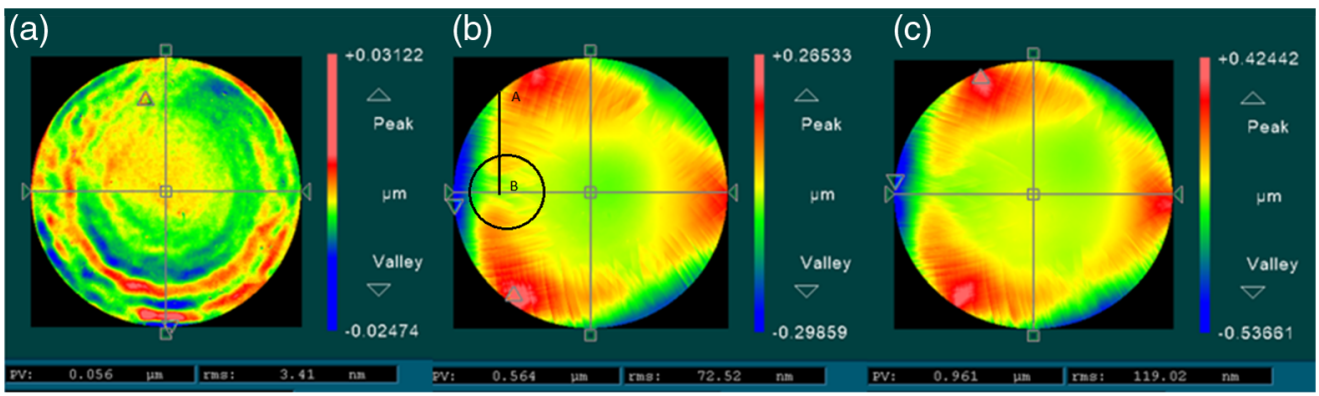

(d)

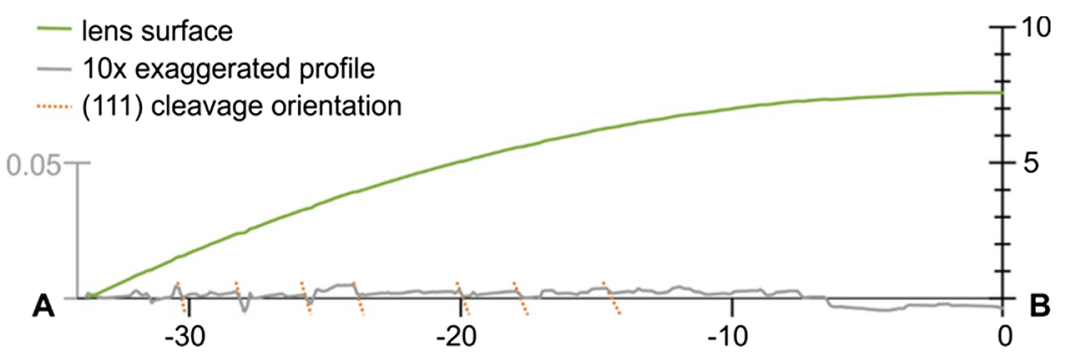

Fig. 3 The L1 R 84.123 CX surface shape measured by ASI: (a) before annealing; (b) after annealing at $350^{\circ} \mathrm{C}$; and (c) after annealing at $500^{\circ} \mathrm{C}$. The significant increase of the RMS surface error value is evident. (d) Profile along the A-B cut shows $10 \times$ exaggerated surface morphology together with (111) cleavage plane orientation. Axes scale is in $\mathrm{mm}$. 


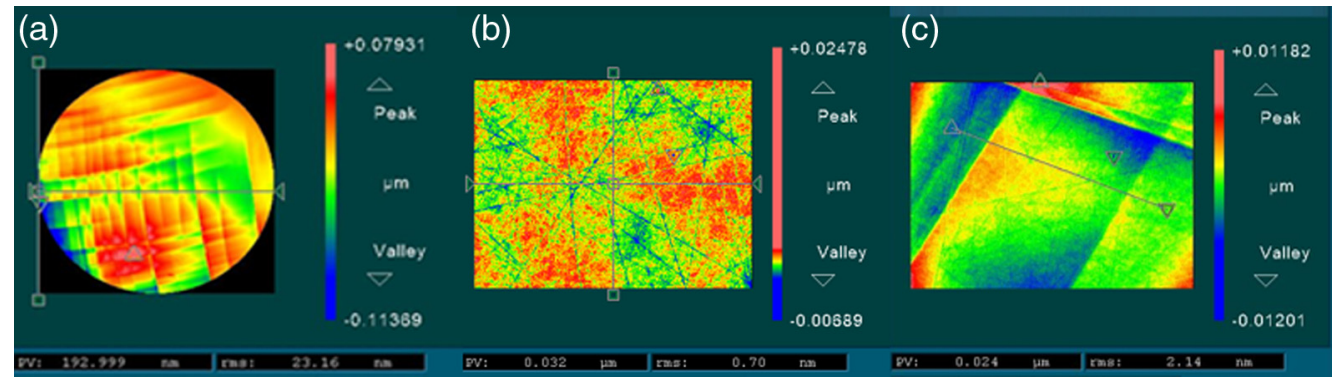

Fig. 4 The L1 R $84.123 \mathrm{CX}$ : (a) the ASI surface subaperture (diameter of $24 \mathrm{~mm}$ ) with characteristic surface structure caused by annealing at $350^{\circ} \mathrm{C}$ (its location is presented by the circle in Fig. 3); (b) the example of $5 \times$ WLI microroughness under $1 \mathrm{~nm}$ RMS before annealing; and (c) the example of $5 \times$ WLI microroughness over $2 \mathrm{~nm}$ RMS after annealing.

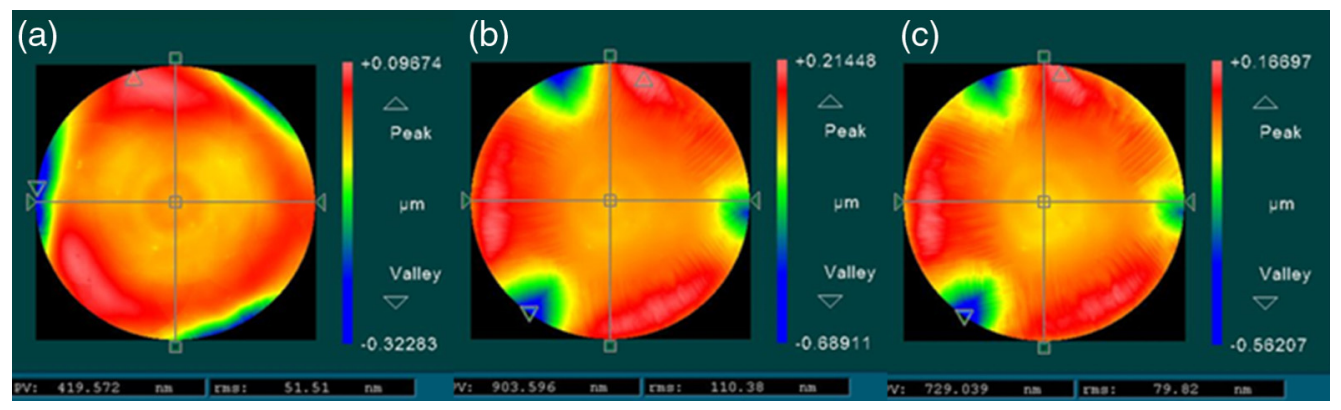

Fig. 5 The L1 R $84.132 \mathrm{CX}$ surface shape after grinding and polishing: (a) before annealing and (b) after first annealing at $350^{\circ} \mathrm{C}$, and (c) after second annealing at $350^{\circ} \mathrm{C}$.

at an angle of $120 \mathrm{deg}$ (Fig. 3), the orientation of which mimics the surface morphology after lens surface processing (Fig. 1). The intensity of the surface deformation increases toward the edges of the lens, being lowest in the center of the lens. The surface highs and lows are formed by oriented terraces and steps showing characteristic $\sim 120$ - deg step-crossing patterns (Fig. 4 ). The height of the steps ranges from $\sim 1$ to $\sim 50 \mathrm{~nm}$ and generally increases toward the edges of the lens. In zones of seemingly low interference between steps of different orientations, the resulting terraces are, in profile, subhorizontal and thus subparallel to the (111) cleavage planes (Fig. 3).

The results of the second phase of the experiments are summarized in Fig. 5. The initial shape after repolishing was redeformed by annealing at $350^{\circ} \mathrm{C}$. In contrast to the results obtained in the first phase, in this case, repeated annealing at $350^{\circ} \mathrm{C}$ led to a change in the degree of deformation (its decrease). Furthermore, a change of positions of the measured minima and maxima (at the same orientation of the measured surface) was observed. The morphology of the surface after the second phase is characterized by similar step-and-terrace character as it was after the first phase of the experiment.

Finally, the results of the third phase are shown in Fig. 6, where it is evident that the shape deformation and structure formation is minimal in comparison with previous experiments performed in the first and second phases. However, the surface still exhibits a characteristic 120-deg step-and-terrace morphology that is most pronounced in the area of a small protuberance in the center of the lens.

All obtained results regarding shape deformation from the performed annealing experiments are summarized in Table 3, where $\Delta$ surface error means the difference between the shape error measured by ASI after and before the annealing process steps expressed in RMS units.

\section{Discussion}

Annealing and polishing experiments were performed with the aim to monitor changes in optical surface shape and structure. Based on a theoretical analysis of the obtained results, the following hypothesis of the observed occurrence causation was determined. 


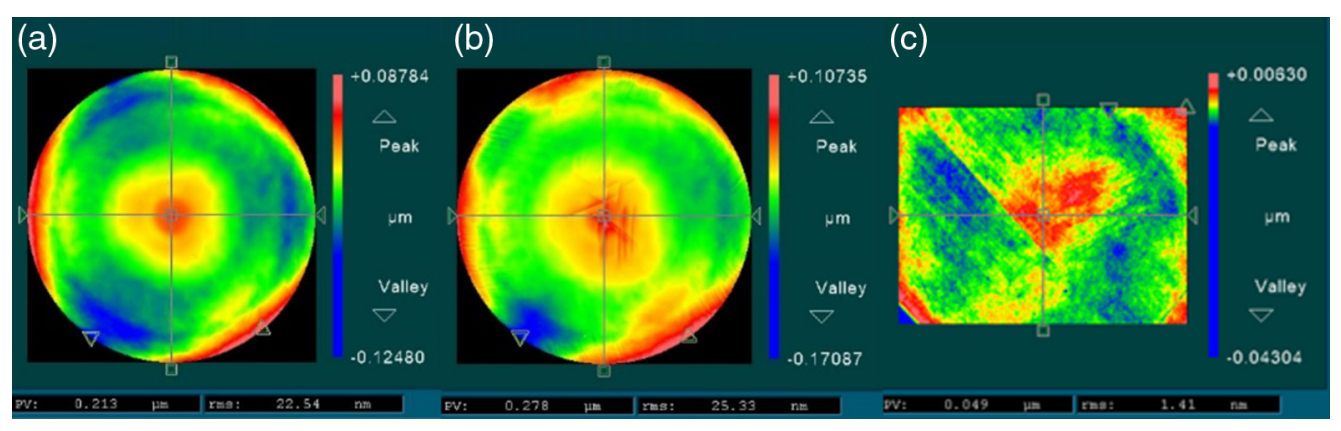

Fig. 6 The L1 R 84.132 CX surface shape after third repolishing: (a) before annealing, (b) after second annealing at $350^{\circ} \mathrm{C}$, and (c) characteristic surface microroughness.

Table 3 Annealing experiment summarization.

\begin{tabular}{lcccccc}
\hline \hline Phase & \multicolumn{2}{c}{ Annealing $350^{\circ} \mathrm{C}$} & \multicolumn{2}{c}{ Annealing $350^{\circ} \mathrm{C}$} & \multicolumn{2}{c}{ Annealing $500^{\circ} \mathrm{C}$} \\
\hline$\Delta$ Surface error (nm RMS) & L1 A & L1 B & L1 A & L1 B & L1 A & L1 B \\
\hline 1 & 70 & 68 & 69 & 71 & 114 & 111 \\
$2^{\mathrm{a}}$ & 161 & 148 & 131 & 126 & - & - \\
3 & 1 & 3 & 3 & 2 & - & - \\
\hline \hline
\end{tabular}

${ }^{\text {aD }}$ ue to change of shape deformation orientation, RMS values were added.

The processing of a $\mathrm{CaF}_{2}$ single crystal into a (a)spherically shaped lens introduces several types of defects into the crystal lattice that can change the stored stress distribution. During classical polishing on an optical pitch pad with water-based polishing slurry, the $\mathrm{Ca}-\mathrm{F}$ bonds are hydrolysed and $\mathrm{F}$ atoms are replaced by $-\mathrm{OH}$ groups in surface layers, whereby point defects are introduced into the $\mathrm{CaF}_{2}$ crystal lattice. ${ }^{19}$ The irradiation due to energetic ion bombardment is a source of color centers formed by vacancies in the crystal lattice. ${ }^{13,20}$ The crystallographically conditioned anisotropy in hardness and material removal mechanisms of the $\mathrm{CaF}_{2}$ single crystal leads to the anisotropy of stored energy and damage type. ${ }^{7,9,11}$ In the regions of ductile deformation, damage is represented by dislocations and the dislocation density decreases toward the regions of brittle deformation, where cleavage microcracks prevail.

The annealing process at high temperature leads to the removal of the point defects, initializations of dislocation climb and glide, and probably to microcrack healing. All of these processes are crystallographically determined and thus could lead to the deformation of the lens shape during annealing. However, in the common case of deformed crystalline materials, almost all of the stored energy is derived from the accumulation of dislocations. The essential difference between the deformed and the annealed states lies in the dislocation content and arrangement. ${ }^{18}$ The observed deformation of the lens surface also resembles, by its orientation and symmetry, the slip steps and cleavage steps observed on the deformed or indented $\mathrm{CaF}_{2}$ (111) surfaces ${ }^{21-23}$ and their possible step-crossing patterns. ${ }^{24}$ The periodically varying regions of highs and lows after annealing coincide with a characteristic surface shape after mechanical processing of lens shapes (Fig. 1) due to a variation of the material removal rates caused by anisotropy in hardness and material removal processes. Moreover, repeated annealing shows that surface deformation prevails over removal of color centers. This can be explained by the fact that the mobility of point defects, such as vacancies and interstitials, is very high compared with the movement of dislocations during annealing. ${ }^{18}$ The energy stored in the crystal lattice by dislocations is thus released significantly more slowly. The observed 120-deg character of the step-crossing patterns and reconstructed profiles suggests that these steps can be interpreted as cleavage steps. Based on this, we can speculate on the likely orientations of the crystal with respect to the surface deformation observed (Fig. 7). 

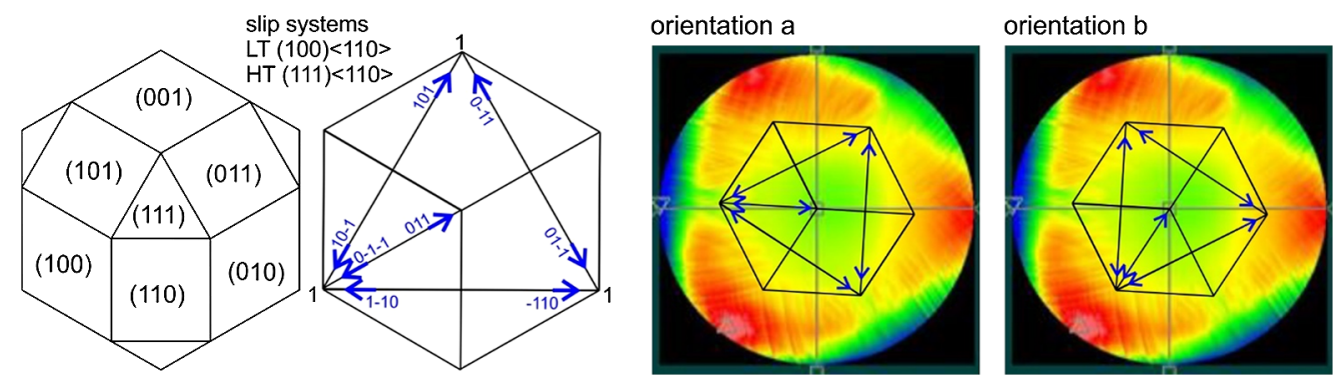

Fig. 7 Illustration showing the main $\mathrm{CaF}_{2}$ crystallographic planes, low $(\mathrm{LT})$ and high $(\mathrm{HT})$ temperature slip systems, and likely orientations of the $\mathrm{CaF}_{2}$ crystal.

The repeated annealing and polishing have been successful in the correction of the surface deformation. This could indicate that most of the damage and stored stress is due to the primary shaping of the lenses, not by final polishing. To avoid the anisotropic behavior of a $\mathrm{CaF}_{2}$ crystal during material removal, Chen et al. ${ }^{10}$ suggested adjusting the contact pressure during surface processing to a certain level, ensuring that the same material removal mechanism operates in all crystallographic directions. In addition to that, we suggest applying variation of the contact pressure during surface processing (mainly during grinding) based on the known orientation of the main crystallographic direction of a machined $\mathrm{CaF}_{2}$ crystal, which would decrease the damage introduced to the crystal lattice and thus, probably, the deformation of the surface during annealing.

\section{Conclusions}

Based on the acquired theoretical knowledge and performed experiments, a hypothesis of the shape deformation and the surface microroughness behavior of optical elements made from a single $\mathrm{CaF}_{2}$ crystal at annealing was established. When processing an oriented single $\mathrm{CaF}_{2}$ crystal (111), there is an increase in the number of defects and dislocations in the crystal structure, which leads to an increase in the anisotropy of the crystallographic properties and to an internal stress rise. The annealing process then leads to the removal of these defects, microcracks, and dislocations and to a further decrease in internal stress. Since the most likely main source of defects is grinding, by alternating the process of annealing at $300^{\circ} \mathrm{C}$ and subsequent polishing, both shape deformation and change in microroughness can be (after initially increasing) gradually minimized, up to values where optical properties are no longer significantly affected. This was verified during the realization of the $\mathrm{CaF}_{2} \mathrm{~L} 1$ and $\mathrm{L} 2$ lenses of the FLORIS telescope, which, as a result of this procedure, met all of the prescribed specifications (Fig. 8).

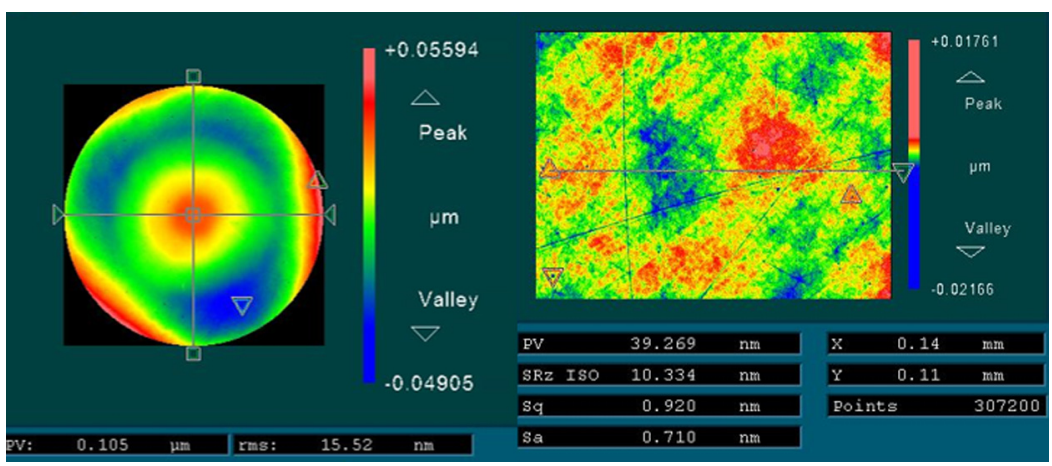

Fig. 8 The FLORIS telescope L1 lens R 84.132 CX: resulting surface shape error $15.5 \mathrm{~nm}$ RMS and microroughness $0.92 \mathrm{~nm}$ RMS. 


\section{Acknowledgments}

This work was carried out within the framework of the "Partnership for Excellence in Superprecise Optics" project (Reg. No. CZ.02.1.01/0.0/0.0/16_026/0008390) and cofunded from European Structural and Investment Funds. M. Machek was supported by the Czech Academy of Sciences institutional support to the Institute of Geophysics of the CAS, v.v.i. (RVO 67985530).

\section{References}

1. P. Coppo et al., "Fluorescence imaging spectrometer (FLORIS) for ESA FLEX mission," Remote Sens. 9, 649 (2017).

2. D. Hahn, "Calcium fluoride and barium fluoride crystals in optics," Opt. Photonik 9, 45-48 (2014).

3. D. H. Kim et al., " $\mathrm{CaF}_{2}$ lens machining optimization by using the laser assisted DTM," Proc. SPIE 11487, 114871J (2020).

4. Y. Namba et al., "Ultra-precision float polishing of calcium fluoride single crystals for deep ultra violet applications," CIRP Ann. 53(1), 459-462 (2004).

5. J. Wang, C. R. Clar, and H. Schreiber, "Extended lifetime of fluoride optics," Proc. SPIE 6720, 67200I (2007).

6. D. Golini et al., "MRF polishes calcium fluoride to high quality," Optoelectr. World Suppl. Laser Focus World 37, S5-S7 (2001).

7. L. Ladison et al., "Hardness, elastic modulus, and fracture toughness bulk properties in corning calcium fluoride," Proc. SPIE 5754, 1329-1338 (2010).

8. Q. Zhang and J. C. Lambropoulos, "Residual stress model for $\mathrm{CaF}_{2}$," J. Mater. Res. 22(10), 2796-2808 (2007).

9. J. Yan, K. Syoji, and J. Tamaki, "Crystallographic effects in micro/nanomachining of singlecrystal calcium fluoride," J. Vac. Sci. Technol. B 22, 46 (2004).

10. L. Chen et al., "Effect of crystallographic orientation on mechanical removal of $\mathrm{CaF}_{2}$," Wear 376-377, 409-416 (2017).

11. Y. Mizumoto and Y. Kakinuma, "Revisit of the anisotropic deformation behavior of singlecrystal $\mathrm{CaF}_{2}$ in orthogonal cutting," Precis. Eng. 53, 9-16 (2018).

12. M. A. Lodes et al., "Influence of dislocation density on the pop-in behavior and indentation size effect in $\mathrm{CaF}_{2}$ single crystals: experiments and molecular dynamics simulations," Acta Mater. 59(11), 4264-4273 (2011).

13. V. Vojtěch et al., "Defects in $\mathrm{CaF}_{2}$ caused by long-time irradiation and their response to annealing," Philos. Mag. 90(20), 2749-2769 (2010).

14. W. Chen et al., "Determination of color centers in $\mathrm{CaF}_{2}$ crystals by multiple gamma-ray irradiations," Chin. Sci. Bull. 58, 1321-1324 (2013).

15. P. Baumeister, Optical Coating Technology, SPIE Press, Bellingham, Washington, DC (2004).

16. P. Feltham and R. Ghosh, "High-temperature stress relaxation of $\mathrm{CaF}_{2}$ crystals," Phys. Status Solidi A 5, 279 (1971).

17. A. Muñoz, A. Domínguez-Rodríguez, and J. Castaing, "Slip systems and plastic anisotropy in $\mathrm{CaF}_{2}$," J. Mater. Sci. 29, 6207-6211 (1994).

18. J. Humphreys, G. S. Rohrer, and A. Rollett, Recrystallization and Related Annealing Phenomena, 3rd ed., Elsevier, Amsterdam, Netherlands (2013).

19. H. Shi et al., "Ab initio calculations of hydroxyl impurities in $\mathrm{CaF}_{2}$," J. Phys. Chem. C 116(10), 6392-6400 (2012).

20. N. Itoh and A. M. Stoneham, Materials Modification by Electronic Excitation, Cambridge University Press (Virtual Publishing), The Pitt Building, Cambridge (2003).

21. J.B. Engelhardt, H. Dabringhaus, and K. Wandelt, "Atomic force microscopy study of the $\mathrm{CaF}_{2}$ (111) surface: from cleavage via island to evaporation topographies," Surf. Sci. 448(2-3), 187-200 (2000).

22. K. Niki, G. Mochimaru, and H. Shindo, "Participation of $\left\{\begin{array}{lllll}1 & 0 & 0\end{array}\right\}\left\langle\begin{array}{lll}0 & 1 & 1\end{array}\right\rangle$ slip system in sliding friction at $\left(\begin{array}{lll}0 & 0 & 1\end{array}\right),\left(\begin{array}{lll}1 & 1 & 1\end{array}\right)$ and $\left(\begin{array}{lll}1 & 1 & 0\end{array}\right)$ surfaces of fluorite $\left(\mathrm{CaF}_{2}\right)$ crystal," Tribol. Online 7(2), 81-86 (2012). 
23. J. Gong et al., "Stress-enhanced dissolution and delamination wear of crystal $\mathrm{CaF}_{2}$ in water condition," Wear 418-419, 86-93 (2019).

24. V. E. Puchin et al., "Theoretical modelling of steps on the $\mathrm{CaF}_{2}$ (111) surface," J. Phys. Condens. Matter 13, 2081-2094 (2001).

Frantisek Prochaska, $\mathrm{PhD}$, is a research worker at the TOPTEC Centre, where he focuses on high-precision CNC machining of aspheric and free-form optical surfaces made from a wide range of glass and crystalline materials, especially on subaperture polishing processes and mid-spatial frequencies suppression. He participated in the implementation of aspheric production technologies in the Meopta Company and significantly contributed to the development of machining processes for, and subsequently to the realization of, the Metis space coronagraph aspheric mirrors, as well as to the technology development for the production of the Neosted and Floris telescope aspheric optical elements.

Biographies of the other authors are not available. 